Brit. J. industr. Med., 1954, 11, 140.

\title{
THE TOXICITY OF NITROGEN PENTOXIDE
}

BY

\author{
W. M. DIGGLE and J. C. GAGE \\ From the Imperial Chemical Industries Ltd., Industrial Hygiene Research Laboratories, \\ Welwyn, Herts
}

(RECEIVED FOR PUBLICATION NOVEMBER 1, 1953)

There is no evidence in the literature that nitrogen pentoxide $\left(\mathrm{N}_{2} \mathrm{O}_{5}\right)$, the highest known oxide of nitrogen, has ever been the subject of a toxicological investigation. This gas rapidly breaks down to give nitrogen dioxide and oxygen, but is known to be stabilized by the presence of ozone, and several investigators (Schumacher and Sprenger, 1929; Johnston, 1951) have studied the complex system of equilibria which exists between ozone, oxygen, and the oxides of nitrogen. Gorodetskii (1936) has studied the gaseous products at silent and spark electrical discharges in air and has concluded that in the presence of excess ozone nitrogen pentoxide is the only oxide of nitrogen produced.

Our interest in the toxicity of nitrogen pentoxide was aroused by our preoccupation with the atmospheric contamination in a high-voltage insulator testing installation. The evolution of ozone in the vicinity of the brush discharge which attends this testing is evident by the characteristic odour, and it might be assumed that this gas constituted the chief toxic hazard were it not for the work of Thorp (1941, 1950), who has shown that ozone prepared from pure oxygen has a far lower toxicity than ozone prepared from air, and that the higher toxicity of the latter must be due to nitrogen oxides. Thorp, however, admitted that the toxicity of air containing ozone and nitrogen oxides (calculated as nitrogen dioxide) was greater than might be expected from the known toxicities of pure ozone and nitrogen dioxide.

In view of the observations of Gorodetskii (1936) and other workers it is an attractive hypothesis that the increase in ozone toxicity which accompanies the presence of nitrogen oxides is due to nitrogen pentoxide. The first step to establish this hypothesis is to study the toxicity of this substance. And this is the scope of the present investigation. The extent to which nitrogen pentoxide is responsible for the toxicity of ozone encountered in industrial atmo- spheres, and the steps which should be taken to control such atmospheres, will be the subject of a later communication.

The toxicity of the lower nitrogen oxides, notably of nitrogen dioxide, has been studied by many investigators on account of the occurrence of these gases in " nitrous fumes" encountered in certain industries. There has been, however, little systematic work on the toxicity of pure nitrogen dioxide to the rat, the species selected for the nitrogen pentoxide experiments, and as concentrations of nitrogen pentoxide in air in the absence of ozone cannot be prepared free from nitrogen dioxide, a study of the toxicity of this gas is also included in the present investigation.

\section{Experimental Methods}

Preparation of Nitrogen Dioxide Solutions.-Nitrogen dioxide was prepared by the controlled heating of dry lead nitrate (Addison and Thompson, 1949). The gas was dried over phosphorus pentoxide and condensed to a pale yellow solid in a weighed glass bulb cooled in a mixture of solid carbon dioxide and acetone. Too rapid heating of the lead nitrate resulted in the production of some nitrogen trioxide; batches contaminated in this way were evident by their greenish-blue colour and were rejected. The bulb was re-weighed and then connected to a tube dipping into chloroform and the temperature was allowed to rise. When the bulb was re-cooled, chloroform was drawn in and the bulb was weighed again. The solutions, which varied in strength between 1.0 and $1.5 \%$, were not stable for more than a few hours and were prepared freshly each day.

For the subsequent colorimetric determination of nitrogen dioxide in air and in nitrogen pentoxide solutions, a standard curve was prepared by adding $0 \cdot 1$ $\mathrm{ml}$. of a series of dilutions of the gas in chloroform to $50 \mathrm{ml}$. of the Patty and Petty (1943) modification of the Griess-Ilosvay reagent, in stoppered flasks. The colour was allowed to develop for 20 minutes with occasional shaking and the optical density was read at $520 \mathrm{~m} \mu$. By comparing the standard curve so obtained with a similar one from a series of sodium nitrite solutions, it 
was shown that $54 \%$ of the nitrogen dioxide reacted as nitrite ; a figure somewhat closer to the theoretical $50 \%$ from the equation

$$
2 \mathrm{NO}_{2}+\mathrm{H}_{2} \mathrm{O}=\mathrm{HNO}_{3}+\mathrm{HNO}_{2}
$$

than is the figure of $57 \%$ obtained by Patty and Petty.

Preparation of Nitrogen Pentoxide Solutions.--Nitrogen pentoxide was prepared by the dehydration of fuming nitric acid with phosphorus pentoxide in the presence of ozone (Audrieth, 1950). The gas was absorbed in chloroform contained in a bubbler immersed in a carbon dioxide-acetone freezing mixture. The chloroform solution was analysed by adding $0.1 \mathrm{ml}$. of an appropriate dilution with chloroform to $5 \mathrm{ml}$. water and then determining the nitrate ion by the method of Barnes (1950), which involves the nitration of $2: 4$ xylenol. The solution was also analysed for nitrogen dioxide by the method described in the previous paragraph. The concentration of nitrogen pentoxide in the solution was found to vary between 13 and $23 \%$, and that of nitrogen dioxide between 0.2 and $1 \%$. The solutions were kept cooled with solid carbon dioxide and were stable for at least one week.

Preparation of the Test Atmospheres.-The apparatus for exposing experimental animals to test atmospheres of nitrogen dioxide and nitrogen pentoxide is shown diagrammatically in Fig. 1. The atmospheres were prepared by atomizing a solution of the gas in chloroform at a predetermined rate into a metered stream of air by means of the controlled fluid-feed atomizer described by Gage (1953). The solution was contained in the glass syringe $\mathbf{A}$ from which it was expelled at a known rate through the atomizer $B$ into a stream of air from a compressed air line dried by the silica gel column $\mathrm{C}$ and metered by the rotameter $\mathrm{D}$. The solution was atomized into the mixing chamber $\mathbf{E}$, and the atmosphere was led through a glass tube into the exposure chamber $F$, which

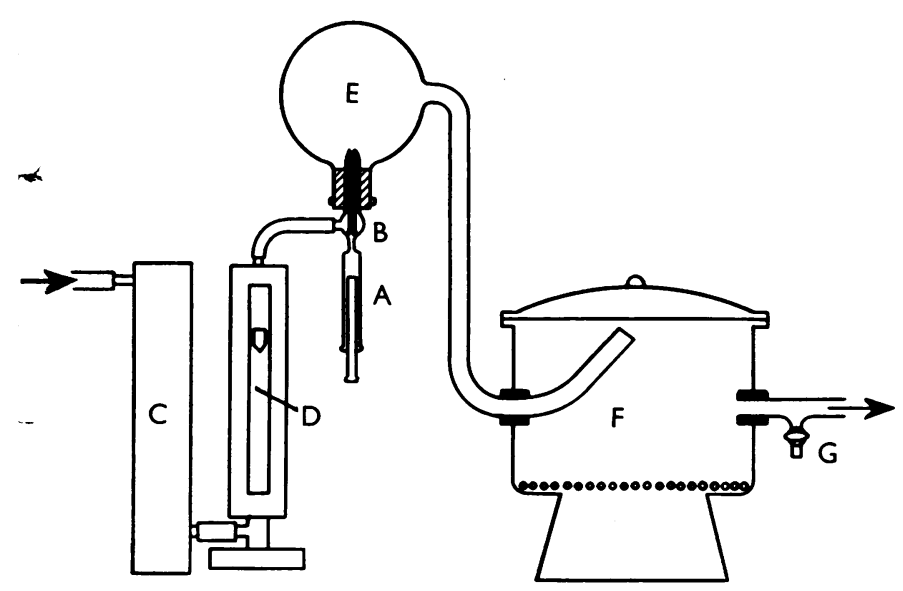

Fig. 1.-Diagram of apparatus for test atmospheres. was constructed from a large glass desiccator bored with inlet and outlet holes and provided with a stainless steel wire mesh grid to support the animals. The exit tube carried a side-arm bearing a stopcock $G$ through which the test atmosphere could be sampled.

In all the animal exposure experiments the air flow was fixed at $51 . / \mathrm{min}$. and the rate of feed of the chloroform solution at $0.00251 \mathrm{ml}$. $/ \mathrm{min}$. ; variations in the test atmosphere were obtained by changing the strength of the chloroform solution. In all these test atmospheres the chloroform concentration was 150 p.p.m. v/v.

Analysis of the Test Atmospheres.-Analyses of the test nitrogen dioxide atmospheres leaving the exposure chamber were made by the method of Patty and Petty (1943). The results established that the predetermined nitrogen dioxide concentrations are maintained in the chamber whether animals are present or not.

Analyses of the nitrogen pentoxide atmospheres were made by drawing a known volume at $200 \mathrm{ml} . / \mathrm{min}$. through two bubblers each containing $1 \mathrm{ml}$. $1 \% 2: 4$ xylenol in glacial acetic acid and $9 \mathrm{ml} .85 \% \mathrm{w} / \mathrm{w}$ sulphuric acid. The tubes were heated at $35^{\circ} \mathrm{C}$. for $30 \mathrm{~min}$., and the contents were then diluted and analysed by the method of Barnes (1950). Nitrogen dioxide also nitrates this reagent to some extent, and experiments have shown that $27 \%$ reacts to give the nitro-derivative. An appropriate correction for the nitrogen dioxide present in the nitrogen pentoxide atmosphere was made after a direct determination of the former by the Patty and Petty method. By this procedure it was shown that about $85 \%$ of the predetermined nitrogen pentoxide concentration could be measured in the air leaving the empty chamber. When animals were present only about onehalf of the expected nitrogen pentoxide was measured; this diminution was attended by a slight increase in the nitrogen dioxide, but this was insufficient to account for the loss of nitrogen pentoxide. The concentrations of the test atmospheres quoted below for the animal experiments are those found by analysis and not the predetermined values.

Although there is no evidence in the literature that nitrogen pentoxide can oxidize chloroform, there is a possibility that a small amount of phosgene might be produced in this way. This contaminant was shown to be absent from an atmosphere containing $25 \mathrm{mg} . / \mathrm{m}^{3}$ nitrogen pentoxide by an appropriate test paper method (Department of Scientific and Industrial Research, 1939), under conditions where 1 p.p.m. $v / v$ of phosgene would have been clearly detectable.

\section{Nitrogen Dioxide Experiments}

Single Exposures.-Male rats, mean weight 208 g., were exposed in groups of three to concentrations of 16 , 40,66 , and $80 \mathrm{mg} . / \mathrm{m}^{3} \mathrm{NO}_{2}$ for four hours. At the lower two concentrations there were no toxic symptoms apart from restlessness; at 66 and $80 \mathrm{mg} . / \mathrm{m}^{3}$ there was some salivation and restlessness and the animals showed slightly laboured breathing towards the end of the 
exposure, but they soon recovered after removal from the atmosphere. Animals killed four and eight days after the exposure showed normal tracheae and lungs.

Similar experiments were made with older male rats ranging in weight from 300 to $400 \mathrm{~g}$. The same symptoms were observed, but some of the animals at the highest concentration showed haemorrhagic patches on the lungs.

Repeated Exposures.-Fourteen male rats, mean weight $185 \mathrm{~g}$., were exposed for four hours a day to 19 mg. $/ \mathrm{m}^{3}{ }^{3} \mathrm{NO}_{2}$ for 16 days. The animals showed no definite signs of discomfort and their breathing was normal. The increase in weight during the experiment was normal. A number of rats were killed at the end of the experiment and the lungs appeared normal.

The experiment was repeated with three rats at a concentration of $62.5 \mathrm{mg} . / \mathrm{m}^{3}$ for four hours a day for 20 days. The animals became restless and towards the end of each day's exposure developed laboured breathing; they recovered overnight and the effect on the respiration was not cumulative. The increase in weight during the period of the exposure was normal. Rats killed at the end of the experiment showed no abnormalities in the lungs.

Histological Examination.-Sections of the lungs of the rats killed after single and repeated exposures to nitrogen dioxide were prepared and stained with haematoxylin and eosin. All appeared normal except those from the large rats which had exhibited haemorrhagic patches on the surface of the lung; in these there was much congestion and extravasation of red cells into the alveoli, but no oedema was apparent.

\section{Nitrogen Pentoxide Experiments}

Single Exposures.-Groups of rats were exposed to a series of concentrations of nitrogen pentoxide for a period of four hours. The effect on the animals is shown in the Table.

TABLE

EFFFCT ON RATS OF A SINGLE 4-HOUR EXPOSURE TO NITROGEN PENTOXIDE

\begin{tabular}{|c|c|c|c|c|c|c|}
\hline \multicolumn{2}{|c|}{$\begin{array}{l}\text { Concen- } \\
\text { tration } \\
\left(\mathrm{mg} . \mathrm{m}^{3}\right)\end{array}$} & \multicolumn{3}{|c|}{ Rats } & \multirow{2}{*}{ Deaths* } & \multirow{2}{*}{ Symptoms } \\
\hline $\mathrm{N}_{2} \mathrm{O}_{5}$ & $\mathrm{NO}_{2}$ & No. & Sex & $\begin{array}{c}\text { Mean } \\
\text { Weight }\end{array}$ & & \\
\hline $5 \cdot 3$ & $2 \cdot 8$ & 4 & q & $200 \mathrm{~g}$. & None & $\begin{array}{l}\text { Salivation and rest- } \\
\text { lessness, later } \\
\text { laboured breath- } \\
\text { ing; rapid re- } \\
\text { covery after } \\
\text { exposure }\end{array}$ \\
\hline $9 \cdot 7$ & $5 \cdot 8$ & 4 & + & $230 \mathrm{~g}$. & $\begin{array}{l}1 \text { ( } 24 \text { hours) } \\
1 \text { (48 hours) }\end{array}$ & $\begin{array}{c}\text { Dyspnoea after } \\
\text { hour }\end{array}$ \\
\hline $12 \cdot 5$ & $2 \cdot 8$ & 6 & 오 & $220 \mathrm{~g}$. & None & Dyspnoea after 1 \\
\hline $\begin{array}{l}13 \cdot 7 \\
20 \cdot 4\end{array}$ & $\begin{array}{l}2 \cdot 3 \\
3 \cdot 5\end{array}$ & $\begin{array}{l}2 \\
4\end{array}$ & q & $\begin{array}{l}225 \mathrm{~g} . \\
350 \mathrm{~g} .\end{array}$ & $\begin{array}{l}1 \text { ( } 12 \text { hours }) \\
2 \text { ( } 2-3 \text { hours }) \\
2 \text { ( } 12-16 \text { hours })\end{array}$ & $\begin{array}{l}\text { fluid at nostrils } \\
\text { Dyspnoea after } 45 \\
\text { min. }\end{array}$ \\
\hline $21 \cdot 3$ & 10 & 4 & 우 & $225 \mathrm{~g}$. & $\begin{array}{l}1 \text { (1 hour) } \\
1 \text { (16 hours) }\end{array}$ & $\begin{array}{l}\text { Immediate dyspnoca, } \\
\text { rapidly becoming } \\
\text { severe; frothy } \\
\text { fluid at nostrils }\end{array}$ \\
\hline
\end{tabular}

* Times in parentheses indicate delay of deaths after end of exposure.
The dyspnoea in these animals was characterized by a gasping inspiration, which in its severe form was attended by a violent contraction of the diaphragm and abdominal muscles.

The severity of the dyspnoea in the animals which survived the exposure decreased after their removal from the atmosphere, and their breathing returned to normal after a few days. All the animals which survived 12.5 $\mathrm{mg}$. $\mathrm{m}^{3}$ and more showed marked inertia for more than a week and during this period they failed to put on weight. In the animals which succumbed to the exposure death was in some cases preceded by violent convulsions ; all the lungs appeared oedematous and emphysematous and there was a frothy, colourless fluid in the tracheae. All the survivors were killed one month after the end of the experiment and the lungs appeared normal.

Repeated Exposures.-Six male rats, mean weight $225 \mathrm{~g}$., were subjected to 10 daily four-hour exposures of $2.5 \mathrm{mg}$. $1 \mathrm{n}^{3}{ }^{3}$ nitrogen pentoxide. From the fourth day onward breathing became somewhat laboured towards the end of each exposure period, with recovery overnight. The mean weight decreased slightly to $215 \mathrm{~g}$. during this experiment. All the animals were killed at the end of the experiment, and the lungs appeared normal.

Six male rats were given 12 daily four-hour exposures of $4 \cdot 25 \mathrm{mg} . / \mathrm{m}^{3}$. During the first three days the animals were restless, and their breathing became laboured towards the end of each exposure period; later, as dyspnoea became more severe, the animals were prostrate. From the seventh day onward a clear fluid appeared at the nostrils. No animal died during the experiment but the mean weight fell from 190 to 150 . Two rats were killed at the end of the exposure and the lungs appeared slightly swollen and emphysematous; in others killed a few days later the lungs appeared normal.

Histological Examination.-Lung sections (Fig. 2) from rats subjected to single exposures of $9.7 \mathrm{mg} . / \mathrm{m}^{3}$ or more of nitrogen pentoxide showed extensive oedema filling large areas of the alveolar space. There was widespread rupture of the alveolar walls, and these patches of emphysema were filled with oedematous fluid. No haemorrhage was apparent, and the alveolar capillaries were not congested. No trace of oedema could be found in the lung sections of rats exposed to repeated concentration of $2.5 \mathrm{mg}$. $\mathrm{m}^{3}$, but at the higher concentration there were small localized areas.

\section{Discussion}

The most notable symptom produced by exposing rats to concentrations of nitrogen pentoxide in air is acute pulmonary oedema, which becomes apparent after a single four-hour exposure to $9.7 \mathrm{mg} . / \mathrm{m}^{3}$ (about 2 p.p.m. v/v). Ten successive daily exposures to $2.5 \mathrm{mg}$. $/ \mathrm{m}^{3}$ (about 0.5 p.p.m. v/v) gave evidence of lung irritation without oedema. It is evident that nitrogen pentoxide must be classed as a "lung irritant" gas, with a potency at least as great as that of phosgene and ketene. 


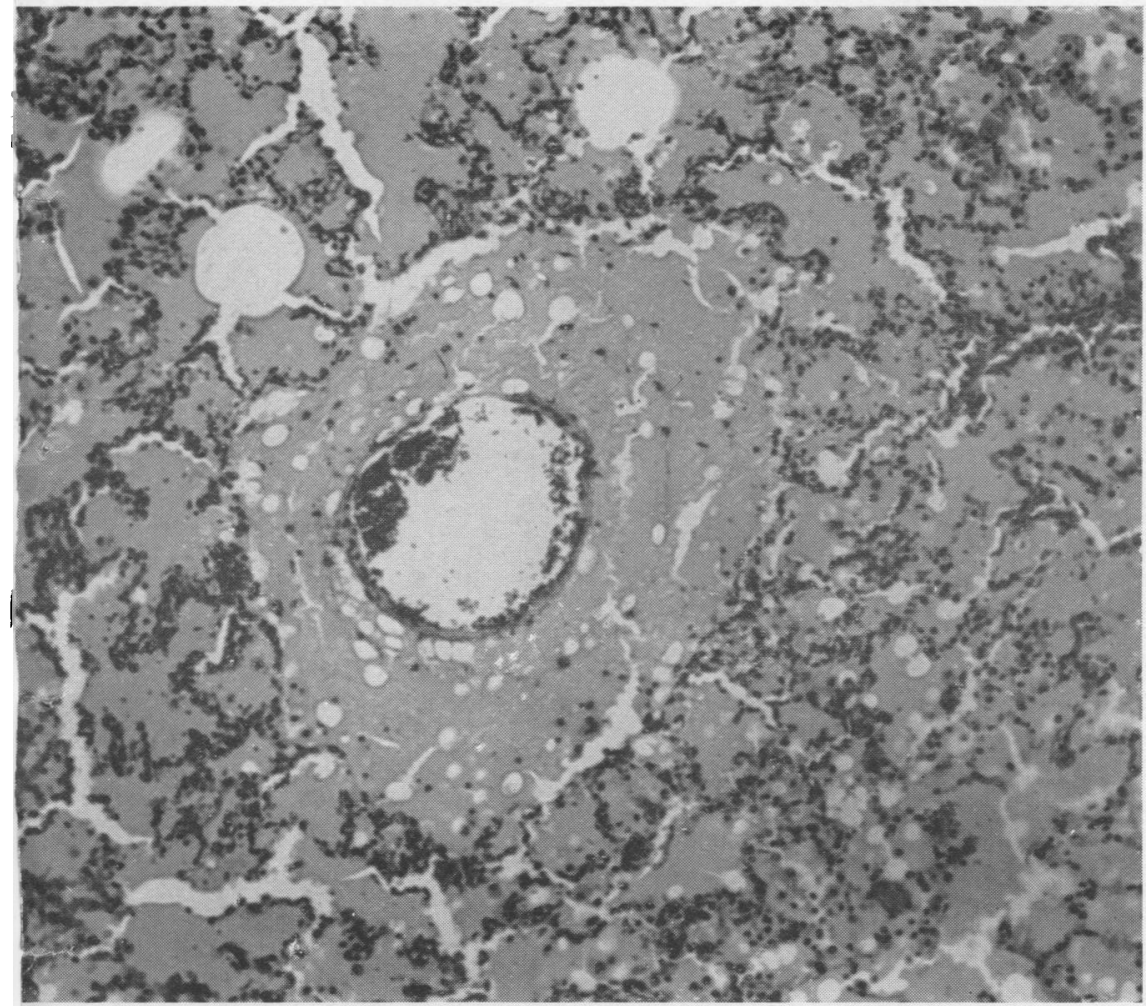

Fig. 2.-Section of rat lung after four-hour exposure to $9.7 \mathrm{mg} . / \mathrm{m} .3$ nitrogen pentoxide showing extensive oedema. $\times 130$.

Nitrogen dioxide, which is the chief constituent of the "nitrous fumes" encountered in industry, appears as a lung irritant of a far lesser intensity. At the highest concentration used in these experiments, $80 \mathrm{mg} . / \mathrm{m} .^{3}$, there was no sign of pulmonary oedema, though a few rats showed haemorrhage of the lung. This is in agreement with statements in the literature that $70 \mathrm{mg} . / \mathrm{m}^{3}$ is well tolerated (McCord, Harrold, and Meek, 1941). The small amount of nitrogen dioxide which unavoidably accompanied the nitrogen pentoxide in our experiments cannot be regarded as contributing significantly to the toxicity of the latter. Chloroform, at the concentration used in all these experiments, is without any detectable effect on the rat from the evidence of the exposures to the lower concentrations of nitrogen dioxide.

To what extent nitrogen pentoxide contributes to the toxicity of " nitrous fumes" is uncertain. It is probable that it is present in ozone produced by an electrical discharge in air, and its contribution to the toxicity of ozone will be discussed in a later communication. It is much less certain that it occurs to any significant extent in the " nitrous fumes" produced by other methods, and so far no method exists for the unequivocal determination of nitrogen pentoxide in a large excess of lower oxides of nitrogen.

Nitrogen pentoxide may be regarded as the anhydride of nitric acid, but its high toxicity cannot be attributed to the acidity produced when it comes into contact with the moisture of the alveolar walls. A similar hypothesis to account for the irritant action of phosgene has been countered by the observation that the amount of acid produced is far too small to have such an effect (Potts, Simon, and Gerard, 1949). There is no direct evidence in the literature that nitric acid vapour when inhaled has any specific irritant action on the lung, other than that derived from its acidity, and experiments in this laboratory have indicated that a single exposure to $63 \mathrm{mg} . / \mathrm{m}^{3}$ of nitric acid has no apparent effect on rats. These considerations lead to the conclusion that an appreciable part of the nitrogen pentoxide diffuses into the alveolar membrane and reacts as such with some component thereof before it reacts with water to form nitric acid. A similar mechanism for the action of phosgene and ketene has been suggested by Potts, Simon, and Gerard (1949).

The analytical method used for the determination of nitrogen pentoxide in air will not distinguish it from nitric acid. It has not, therefore, been possible to determine whether there has been in our experiments some conversion of nitrogen pentoxide to nitric acid by moisture in the atmosphere. If this were so, then the toxicity of nitrogen pentoxide would be even greater than that reported here, though in view of the conclusions which were reached concerning the fate of nitrogen pentoxide in the lungs, it seems improbable that this reaction takes place to any significant extent.

\section{Summary}

Methods are described for the preparation and analysis of test atmospheres of nitrogen dioxide and nitrogen pentoxide. 
Inhalation experiments on rats have shown that nitrogen pentoxide is a lung-irritant gas with a potency of the same order as phosgene. Acute pulmonary oedema is produced by a four-hour exposure to $9.7 \mathrm{mg} . / \mathrm{m}^{3}$ (ca. 2 p.p.m.), or by 12 daily four-hour exposures to $4.25 \mathrm{mg} . / \mathrm{m}^{3}$ (ca. 1 p.p.m.). No oedema, but symptoms of respiratory distress were obtained with 10 daily four-hour exposures to $2.5 \mathrm{mg}$. $\mathrm{m}^{3}$ (ca. 0.5 p.p.m.).

Nitrogen dioxide has a much lower lung irritant action ; $80 \mathrm{mg} . / \mathrm{m} .^{3}$ produces no oedema but a few rats show haemorrhage of the lung at this concentration.

As nitric acid vapour is without obvious effect on rats at $63 \mathrm{mg} . / \mathrm{m} .{ }^{3}$, it is concluded that the toxicity of nitrogen pentoxide does not derive from the nitric acid formed therefrom, but that nitrogen pentoxide reacts directly with some constituent of pulmonary tissue.
We wish to express our indebtedness to Dr. M. W. Goldblatt for his advice on the pathological interpretation of the animal experiments, and to Mr. J. S. Crozier for preparing the lung sections for histological examination.

\section{REFERENCES}

Addison, C. C., and Thompson, R. (1949). J. chem. Soc., S218. Audrieth, L. F. (1950). Inorg. Synth., 3, 78.

Barnes, H. (1950). Analyst, 75, 388.

Department of Scientific and Industrial Research (1939). Methods for the Detection of Toxic Gases in Industry. Leaflet No. 8 , Phosgene. H.M.S.O., London.

Gage, J. C. (1953). J. sci. Instrum., 30, 25.

Gorodetskii, G. A. (1936). Zh. prikl. Khim., Lenirgr., 9, 353.

Johnston, H. S. (1951). J. Amer. chem. Soc., 73, 4542.

McCord, C. P.. Harrold, G. C., and Meek, S. F. (1941). J. industr. Hyg., 23, 200.

Patty, F. A., and Petty, G. M. (1943). Ibid., 25, 361

Potts, A. M., Simon, F. P., and Gerard, R. W. (1949). Arch. Biochem., 24. 329.

Schumacher, H. J., and Sprenger, G. (1929). Z. phys. Chem. A., 140, 281.

Thorp, C. E. (1941). J. Amer. chem. Soc. (News Edn.), 19, 686. -(1950). British Journal of Industrial Medicine, 7, 207. 